\title{
Increased amounts of farnesylated p21Ras in tissues of hyperinsulinaemic animals
}

\author{
M.L. Goalstone ${ }^{1}$, K. Wall ${ }^{1}$, J. W. Leitner ${ }^{1}$, T. Kurowski ${ }^{2}$, N. Ruderman ${ }^{2}$, S.J Pan ${ }^{3}$, J. L. Ivy ${ }^{3}$, D. E. Moller ${ }^{4}$, B. Draznin ${ }^{1}$ \\ ${ }^{1}$ Medical Research Service and Department of Medicine, Veterans Affairs Medical Center and \\ the University of Colorado Health Sciences Center, Denver Colorado, USA \\ ${ }^{2}$ Diabetes and Metabolism Unit, Boston University School of Medicine, Boston, Massachusetts, USA \\ ${ }^{3}$ Exercise Physiology and Metabolism Laboratory, Department of Kinesiology, University of Texas, Austin, Texas, USA \\ ${ }^{4}$ Laboratory of Molecular Endocrinology, Merck \& Co, Rahway, New Jersey, USA
}

\begin{abstract}
Summary We have recently demonstrated that insulin activates farnesyltransferase (FTase) and thereby increases the amounts of cellular farnesylated p21Ras in 3T3-L1 fibroblasts, adipocytes and vascular smooth muscle cells. We postulated that hyperinsulinaemia might considerably increase the the cellular pool of farnesylated p21Ras available for activation by other growth factors. To examine the role of in vivo hyperinsulinaemia in regulating farnesylated p21Ras, we measured the amounts of farnesylated p21Ras in tissues of hyperinsulinaemic animals. Liver, aorta, and skeletal muscle of ob/ob mice, and mice made obese and hyperinsulinaemic by injection of gold-thioglucose contained greater amounts of farnesylated p21Ras than tissues of their lean normoinsulinaemic counterparts. Similarly, farnesylated p21Ras was increased (67 vs $35 \%$ in control animals, $p<0.01)$ in the livers of hyperinsulinaemic Zucker
\end{abstract}

rats (fa/fa). Reduction of hyperinsulinaemia by exercise training ( $2 \mathrm{~h} /$ day for 7-8 weeks) resulted in decreases in the amounts of farnesylated p21Ras in these animals. Increased farnesylated p21Ras in hyperinsulinaemic animals reflected increasing increments in the activity of FTase in ob/ob mice (2-fold increase) and fa/fa Zucker rats (3.5-fold increase), while the total amounts of Ras proteins remained unchanged. In contrast to insulin-resistant hyperinsulinaemic animals, denervated insulin-resistant rat soleus muscle (in the presence of normoinsulinaemia) showed normal amounts of farnesylated p21Ras. In summary, these data confirm increased amounts of farnesylated p21Ras in tissues of hyperinsulinaemic animals. [Diabetologia (1999) 42: 310-316]

Keywords Farnesylated p21Ras, hyperinsulinaemia, farnesyltransferase.
Activation of the Ras signalling pathway by GTP loading of Ras proteins is the critical step that connects the events at the plasma membrane with cellular and nuclear responses [1]. The replacement of p21Ras-bound GDP with GTP is facilitated by guanine nucleotide exchange factors that convert

Received: 11 August 1998 and in final revised form: 27 October 1998

Corresponding author: B. Draznin, M.D., Ph.D.,

Denver VA Medical Center (151), 1055 Clermont Street,

Denver, Colorado 80220, USA

Abbreviations: GAP, GTPase activating protein; FTase, farnesyltransferase; VSMC, vascular smooth muscle cells; GTG, gold-thioglucose; NO, nitric oxide; A II, angiotensin II; AVP, vasopressin; PDGF, platelet derived growth factor; VEGF, vascular endothelial growth factor. inactive p21Ras-GDP proteins into the active p21Ras-GTP conformation, enabling p21Ras-GTP to transduce external signals to internal events [2, 3]. Conversely, the return of the active form of p21Ras into the inactive form is preceded by the hydrolysis of p21Ras-GTP to GDP [1-4], a process that is not only intrinsic to Ras proteins but also increased by the GTPase activating protein (GAP).

Only post-translationally modified Ras proteins (those that are farnesylated and carboxymethylated) are translocated to the plasma membrane whereby they can be activated by the guanine nucleotide exchange factors [5]. Farnesylation of p21Ras is catalyzed by the enzyme farnesyltransferase (FTase) [6, 7] and is an obligatory initial step that targets Ras proteins to the plasma membrane for future activa- 
tion. The farnesyl moiety, an intermediate in the cholesterol synthesis pathway, provides a necessary functional group to p21Ras that allows the anchoring of these proteins at the plasma membrane.

Recent evidence indicates that insulin activates FTase $[8,9]$. Enhanced FTase activity results in notable increases in farnesylated p21 Ras in 3T3-L1 fibroblasts, adipocytes, and vascular smooth muscle cells (VSMC) [8-10]. Farnesylated p21Ras proteins are translocated to and anchored at the plasma membrane where they can be activated by various growth factors and other agents that use the Ras signalling pathway $[5,11]$. We have postulated [10] that hyperinsulinaemia, by means of its influence on the size of the cellular pool of farnesylated p21Ras, creates a favourable milieu for increased activation of the Ras signalling pathway with the potential deleterious consequence of such "hyperactivation".

Since accelerated atherosclerosis and coronary artery disease are commonly associated with hyperinsulinaemia or insulin resistance or both, their pathogeneses is possibly related to the exaggerated responsiveness of the Ras pathway as a result of insulin-induced increases in the cellular pool of farnesylated p21Ras. If this hypothesis is correct, then tissues of hyperinsulinaemic animals should contain greater amounts of farnesylated p21Ras. To examine this possibility, we compared the amounts of farnesylated p21Ras in the aorta, skeletal muscle, and liver of hyperinsulinaemic obese rodents with the same tissues obtained from their lean counterparts. We found that the tissues of hyperinsulinaemic animals indeed contained higher amounts of farnesylated p21Ras. Furthermore, exercise and administration of clenbuterol reduced both hyperinsulinaemia and the tissue content of farnesylated p21Ras.

\section{Materials and methods}

Material. The anti-p21Ras antibody was from Transduction Laboratories (Lexington, Ky., USA). The Triton X-114, phosphate buffered saline (PBS) and all reagents were from Sigma (St. Louis, Mo., USA). Protein G plus protein A agarose and Ras protein were from Calbiochem (La Jolla, Calif., USA); enhanced chemiluminescence (ECL kit) was from Amersham (Arlington Heights, Ill., USA); and the polyacrylamide gels and polyvinylidene difluoride (PVDF) membranes were from Bio-Rad (Hercules, Calif., USA). Tritiated farnesyl pyrophosphate $\left[{ }^{3} \mathrm{H}\right] \mathrm{FPP}(0.5 \mathrm{mCi} / \mathrm{ml}, 22.5 \mathrm{Ci} / \mathrm{mmol})$ was from DuPont New England Nuclear (NEN) (Boston, Mass., USA), and $20 \%$ Intralipid was from Baxter Healthcare (Chicago, Ill., USA).

Animals. Female ob/ob and lean ob/- matched control mice were obtained from Jackson laboratories, (Bar Harbor, Me., USA). In separate C57 BL-6 male mice experimental obesity was created by a single intraperitoneal injection of gold-thioglucose (GTG, Sigma; $0.5 \mathrm{mg} / \mathrm{kg}$ body weight) at 5 weeks of age [12]. Mice were given ad libitum access to food and water and they were killed at 12 (ob/ob and ob/-) or 30 (GTG-obese and matched control mice) weeks of age. Blood (from fed ani- mals) was collected by cardiac puncture at the time of killing; samples were analyzed to determine insulin and glucose concentrations as described previously [13].

Age-matched male Zucker obese (fa/fa) and lean control (fa/-) rats were obtained from Charles River Laboratories (Wilmington, Mass., USA). Animals were fed standard rat chow and water ad libitum until time of kill. They were housed individually or two per cage in a temperature controlled room $\left(21^{\circ} \mathrm{C}\right)$ with a $12 \mathrm{~h}$ light:dark cycle. In experiments with exercise and clenbuterol, the rats were randomly assigned to either a control, clenbuterol or exercise training treatment group. Rats assigned to the exercise training group were running during their dark cycle on a rodent motor-driven treadmill (Quinton Instruments, Seattle, Wash., USA) at an $8 \%$ grade for 7-8 weeks. Both treadmill speed and duration were increased regularly during the first 3 weeks until the rats were running $2 \mathrm{~h}$ per day at $18 \mathrm{~m}$ per min for 5 days per week. During the next 3-4 weeks, the rats were kept on this training schedule. Rats receiving clenbuterol were intubated (oesophagially) with $1 \mathrm{mg} / \mathrm{kg}$ body weight of the selective $\beta 2$ adrenergic agonist (Sigma Chemical, St. Louis, Mo., USA) dissolved in deionized water. Rats were intubated with clenbuterol approximately $30-45 \mathrm{~min}$ before the exercised trained rats started their training run and on the weekends when rats were not being trained. At the same time the control and exercise trained rats were intubated with a similar volume of deionized water as that received by the rats in the clenbuterol treatment group $(0.30-0.35 \mathrm{ml})$. At the end of the experiment the rats were killed with an injection of sodium pentobarbital $(0.2 \mathrm{ml}, 65 \mathrm{mg} / \mathrm{ml})$ and liver rapidly excised and frozen in liquid nitrogen. Plasma glucose was measured by hexokinase/ glucose 6-phosphate dehydrogenase method and plasma insulin was assayed by radioimmunoassay using a kit from Linco Research Inc. (St. Louis, Mo., USA) and a rat insulin standard.

Denervation studies were done in young male SpragueDawley rats (55-65 g) obtained from the Charles River Breeding laboratories (Wilmington, Mass.,USA). Rats were anaesthetized with sodium pentobarbital ( $4 \mathrm{mg} / 100 \mathrm{~g}$ body weight) and denervation of one limb was carried out as described previously [14]. Soleus muscles from denervated and control limbs were obtained for determinations of the amounts of farnesylated p21Ras as described below. Plasma glucose and insulin concentrations remained normal in these animals [15].

Measurements of farnesylated p21Ras. Tissue samples were prepared by weighing $200 \mathrm{mg}$ of designated tissue and lysing them in $1 \mathrm{ml}$ of lysis buffer $(50 \mathrm{mmol} / \mathrm{l} \mathrm{HEPES}, 150 \mathrm{mmol} / \mathrm{l}$ $\mathrm{NaCl}, 5 \mathrm{mmol} / \mathrm{l} \mathrm{MgCl}, 1 \mathrm{mmol} / \mathrm{l}$ phenylmethylsulfonyl fluoride, $1 \mathrm{mmol} / 1 \mathrm{Na}_{2} \mathrm{PO}_{4}, 1 \%$ Triton $\mathrm{X}-100,1 \mathrm{mmol} / \mathrm{l}$ dithiothreitol, $1 \mathrm{mmol} / \mathrm{l}$ sodium vanadate, $0.05 \%$ SDS, $10 \mu \mathrm{g} / \mathrm{ml}$ aprotinin, $10 \mu \mathrm{g} / \mathrm{ml}$ leupeptin, $\mathrm{pH} 7.5)$, using a dounce homogenizer. The crude lysate was centrifuged at $2000 \mathrm{~g}$ for $5 \mathrm{~min}$. The supernatant was normalized for protein to $1 \mathrm{mg} / \mathrm{ml}$. Equal volumes of the diluted lysate and $4 \%$ Triton X-114 were combined in a borosilicate glass tube, vortexed and incubated at $37^{\circ} \mathrm{C}$ for $3 \mathrm{~min}$. Solutions were kept at room temperature until the aqueous (containing unfarnesylated p21Ras) and detergent (containing the farnesylated p21Ras) phases had separated. Equal samples from each phase where placed in separate $1.5 \mathrm{ml}$ tubes and p21Ras was immunoprecipitated using a monoclonal antibody (Y13-259). Relative amounts of p21Ras were determined by Western blotting followed by densitometry [8]. In several experiments the total of cellular Ras was determined by immunoprecipitation of Ras protein from the whole cell lysate followed by immunoblotting with antip21Ras antibody, Y13-259. 
In vitro measurement of farnesyltransferase activity. Tissues were lysed as described above and normalized for protein. The in vitro filtration assay was initiated by adding a 5 - $\mu$ l aliquot of diluted extract to $45 \mu$ l of the reaction assay solution (5 mmol/1 $\mathrm{MgCl}_{2} 5 \mathrm{mmol} / \mathrm{l}$ dithiothreitol, $100 \mathrm{nmol} / \mathrm{l}$ Ras protein, $100 \mathrm{nmol} / \mathrm{l}$ tritiated farnesyl pyrophosphate $(15 \mathrm{mCi} /$ $\mathrm{mmol}$ ), $50 \mathrm{mmol} / \mathrm{l} \mathrm{HEPES}, \mathrm{pH} 7.5$ ) and incubated at $37^{\circ} \mathrm{C}$ for $30 \mathrm{~min}$. The assay was stopped by adding $1 \mathrm{ml}$ of ice-cold $1 \mathrm{~mol} / \mathrm{l} \mathrm{HCl}$ in ethanol and placed on ice for $15 \mathrm{~min}$. Reaction solutions were transferred to borosilcate glass tubes $(12 \times 75 \mathrm{~mm})$ along with $2 \mathrm{ml}$ of ice-cold ethanol. Solutions were filtered through Whatman GF/C glass-fibre filters. Each filter was air dried, placed into a scintillation vial with $3.5 \mathrm{ml}$ scintillation fluid, and quantified by liquid scintillation spectrometry. The in vitro FTase assay was linear with respect to time and extract protein [8].

Statistical analysis. Data were analyzed by Student's paired or unpaired $t$ test with a $p$ value less than 0.05 considered significant.

\section{Results}

In initial experiments we compared the amounts of farnesylated p21Ras in three tissues derived from obese (ob/ob) and lean (ob/-) mice: aorta, skeletal muscle, and liver. As expected, ob/ob mice (female, 12 weeks of age) were both hyperinsulinaemic $(2.6 \pm 0.03 \mathrm{nmol} / \mathrm{l}$ vs $47 \pm 2 \mathrm{pmol} / \mathrm{l})$ and hyperglycae$\mathrm{mic}(19.6 \pm 2 \mathrm{mmol} / \mathrm{l}$ vs $11.2 \pm 0.5 \mathrm{mmol} / \mathrm{l})$. Farnesylated p21Ras was extracted from tissue homogenates with Triton X-114 as described in Methods. The amounts of farnesylated p21Ras in the obese animals were significantly $(p<0.05)$ increased in all three tissues studied (Fig.1A). The magnitude of increase over the amounts found in lean mice was similar in all three tissues. Similar results were obtained in experiments with C57BL6 mice (male, 30 weeks of age) made obese and hyperinsulinaemic (11.2 \pm 3 $\mathrm{nmol} / \mathrm{l} \mathrm{vs} 598 \pm 91 \mathrm{pmol} / \mathrm{l}$ in control mice) by injection of gold-thioglucose (GTG), $0.5 \mathrm{mg} / \mathrm{kg}$ body weight intraperitoneally at 5 weeks of age. Despite the higher levels of insulinaemia in GTG-obese mice, mean fed glucose concentrations were identical in control and GTG-obese hyperinsulinaemic animals $(12.1 \pm 0.4 \mathrm{mmol} / 1 \quad$ vs $12.5 \pm 0.6 \mathrm{mmol} / \mathrm{l})$. The amounts of farnesylated p21Ras were significantly increased $(p<0.05)$ in aorta, skeletal muscle, and liver of hyperinsulinaemic GTG-obese mice (Fig. 1B).

We then measured the amounts of farnesylated p21 Ras in livers of hyperinsulinaemic Zucker rats. Since all three tissues had shown identical levels of farnesylated p21Ras, we carried out subsequent measurements only in the liver, using it as the representative tissue (Fig.2). As shown in Figure 2, the levels of farnesylated p21Ras were increased in young Zucker rats $(\mathrm{fa} / \mathrm{fa})(67 \pm 6 \%$ vs $35 \pm 5 \%$ in control rats, $p<0.01)$. Even though the weights of these young $\mathrm{fa} / \mathrm{fa}$ rats were identical to their age-matched lean
Table 1. Body weight and levels of insulinaemia and glycaemia in Zucker rats

\begin{tabular}{lllcc}
\hline Group & $n$ & $\begin{array}{l}\text { Weight } \\
(\mathrm{g})\end{array}$ & $\begin{array}{l}\text { Insulin } \\
(\mathrm{nmol} / \mathrm{l})\end{array}$ & $\begin{array}{l}\text { Glucose } \\
(\mathrm{mmol} / \mathrm{l})\end{array}$ \\
\hline 1. Lean (fa/-) & 9 & $169 \pm 7$ & $0.36 \pm 0.08$ & $4.9 \pm 0.4$ \\
2. Zucker (fa/fa) & 8 & $177 \pm 10$ & $1.44 \pm 0.41^{\mathrm{a}}$ & $5.7 \pm 0.4$ \\
3. Zucker (control) & 7 & $322 \pm 8$ & $3.4 \pm 0.64$ & $5.6 \pm 0.2$ \\
4. Zucker (Exercise) & 9 & $307 \pm 7$ & $2.0 \pm 0.37^{\mathrm{b}}$ & $4.8 \pm 0.2$ \\
5. Zucker (Clenbuterol) & 7 & $324 \pm 4$ & $1.96 \pm 0.04^{\mathrm{b}}$ & $5 \pm 0.24$ \\
6. Lean (fa/-) & 6 & $302 \pm 6$ & $1.1 \pm 0.32^{\mathrm{b}}$ & $5.3 \pm 0.8$ \\
\hline
\end{tabular}

${ }^{\mathrm{a}}, \mathrm{p}<0.05$ vs Group 1; ${ }^{\mathrm{b}}, \mathrm{p}<0.01$ vs Group 3 .

Data are means \pm SEM with the number of animals in a designated group indicated in the column " $n$ "

control rats (Table 1: Groups $1 \& 2$ ), the fa/fa animals were substantially hyperinsulinaemic.

To assure that the tissue fat content did not affect the partitioning of the farnesylated Ras into the detergent phase, we carried out the following experiments. Firstly, we added $20 \%$ Intralipid $(50 \mu \mathrm{l})$ to an aliquot of normal tissue lysate before the detergent extraction. Triton X-114 extracted equal amounts of endogenous farnesylated p21Ras into the detergent (d) phases of the control and lipid-containing lysates (Fig. 3A). Secondly, we repeated the above procedure but added $250 \mathrm{nmol} / 1$ of unprocessed recombinant p21Ras to the control and lipid-containing lysates before Triton X-114 extraction. Recovery of p21Ras in the aqueous (a) phases of the two lysates was identical (Fig. 3B). Taken together, these experiments indicate that the fat present during Triton X-114 extraction does not affect the partitioning or recovery of p21Ras in either aqueous or detergent phases.

Increases in farnesylated p21 Ras might reflect the overall increases of Ras proteins in the hyperinsulinaemic rodents. To investigate this possibility we compared the total amounts of Ras proteins in liver samples obtained from ob/ob and ob/- mice as well as fa/ fa and fa/- Zucker rats. The total amounts of Ras proteins analyzed by Western blotting were identical in obese hyperinsulinaemic and lean normoinsulinaemic animals (not shown), suggesting that only the fraction of farnesylated p21 Ras is influenced by hyperinsulinaemia.

We have shown previously that in cultured cells exposed to insulin, increases in cellular farnesylated p21Ras reflected an increased activity of FTase [8-10]. To confirm that the increases in farnesylated p21Ras observed in the tissues of hyperinsulinaemic animals also resulted from increased activity of FTase, we measured the latter in liver extracts of ob/ $\mathrm{ob}$ and ob/- mice, and fa/fa and fa/- Zucker rats. As depicted in Figure 4, FTase activity was significantly increased in livers of hyperinsulinaemic animals compared with control animals.

If hyperinsulinaemia promotes increases in farnesylated p21Ras, reductions in the levels of insulin- 


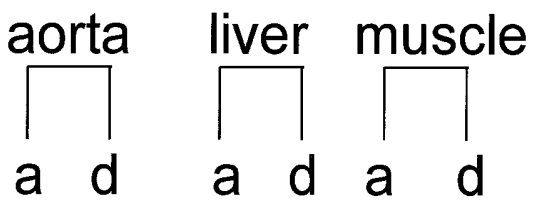

ob/ob

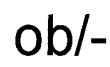

A

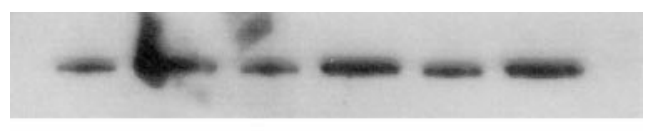

$\mathrm{ob} /-$

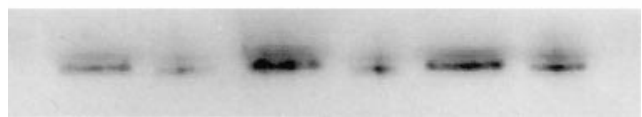

lean

\section{GTG-obese}

aorta liver muscle

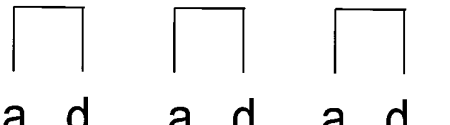

a d a d a d

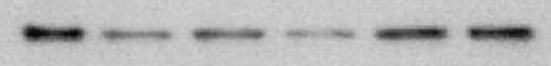

C
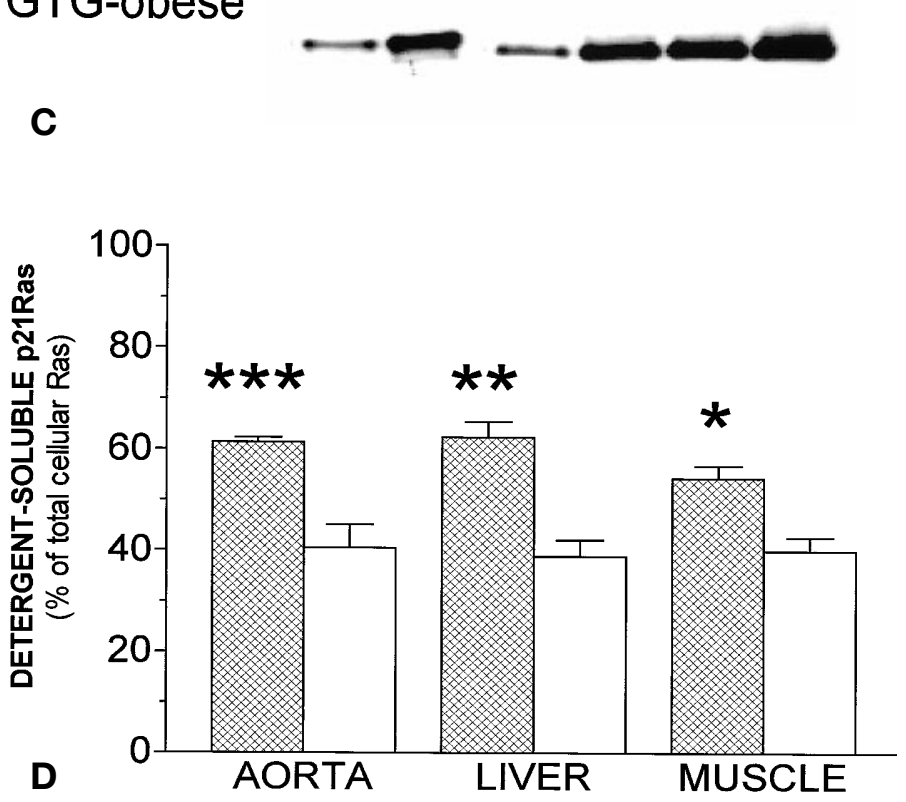

Fig.1A-D. Amounts of farnesylated (detergent-soluble) p21Ras in murine tissue. Crude lysates were prepared from aorta, liver and skeletal muscle of obese and lean mice as described in Methods. p21Ras was extracted from the aqueous (a) and detergent (d) phases of the indicated tissue, determined by Western blotting ( $\mathbf{A}$ and $\mathbf{C}$ ) and quantified by densitometry ( $\mathbf{B}$ and $\mathbf{D})$. Results are expressed as the amounts of farnesylated p21Ras in tissues of ob/ob (solid bars) and ob/(hatched bars) mice (A and B), as well as from similar tissues of GTG-obese (cross-hatched bars) and control-lean (open bars) mice ( $\mathbf{C}$ and $\mathbf{D})$. Results represent means $\pm \mathrm{SEM}$, ***, $p<0.001$ vs lean; ${ }^{*}, p<0.01$ vs lean; ${ }^{*}, p<0.05$ vs lean $(n=5)$

aemia should result in decreases of farnesylated Ras proteins. Therefore, in the next series of experiments we assessed the impact of the amelioration of insulin resistance and the reduction in the levels of insulinaemia on the amounts of farnesylated p21Ras. One group of Zucker rats (Table 1, Group 4) was exercised for 7 weeks, 90 min per day, whereas another group of Zucker rats (Table 1, Group 5) was treated with clenbuterol, a beta-adrenergic agonist that has previously been shown to improve insulin sensitivity in Zucker rats $[16,17]$. Both exercise and the treatment with clenbuterol reduced the levels of insulinaemia in obese Zucker rats ( Table 1). This was accompanied by significant $(p<0.05)$ reductions in the liver content of farnesylated p21Ras (Fig.5) in both

treatment groups compared with control Zucker rats (Group 3) $(46 \pm 2 \%$ in exercise group, $47 \pm 4 \%$ in clenbuterol group, and $58 \pm 2 \%$ in the untreated group). After the treatment the animals remained, however, hyperinsulinaemic and had higher amounts of farnesylated p21Ras than fa/- animals (Fig. 2).

Finally, we determined the amounts of farnesylated p21Ras in control and denervated soleus muscle. The latter has been shown to be insulin-resistant in the absence of hyperinsulinaemia $[14,15]$. The percentages of farnesylated p21Ras were nearly identical in control $(46 \pm 5 \%)$ and denervated $(45 \pm 2 \%)$ soleus muscle (Fig. 6).

\section{Discussion}

Our study supports our hypothesis that hyperinsulinaemia might influence cellular responsiveness to growth promoting agents by increasing the pool of farnesylated p21Ras available for activation. The question whether or not hyperinsulinaemia, a hallmark of insulin resistance, exerts its own detrimental influence on the arterial wall is central to this important health care problem and remains to be elucidated. Numerous correlative studies have demonstrated an association of hyperinsulinaemia and insulin resistance with atherosclerosis and coronary artery disease [18-20]. The mechanism that is responsible for 
fa / -
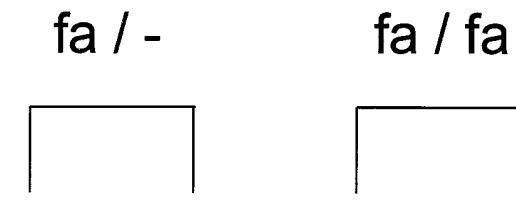

a
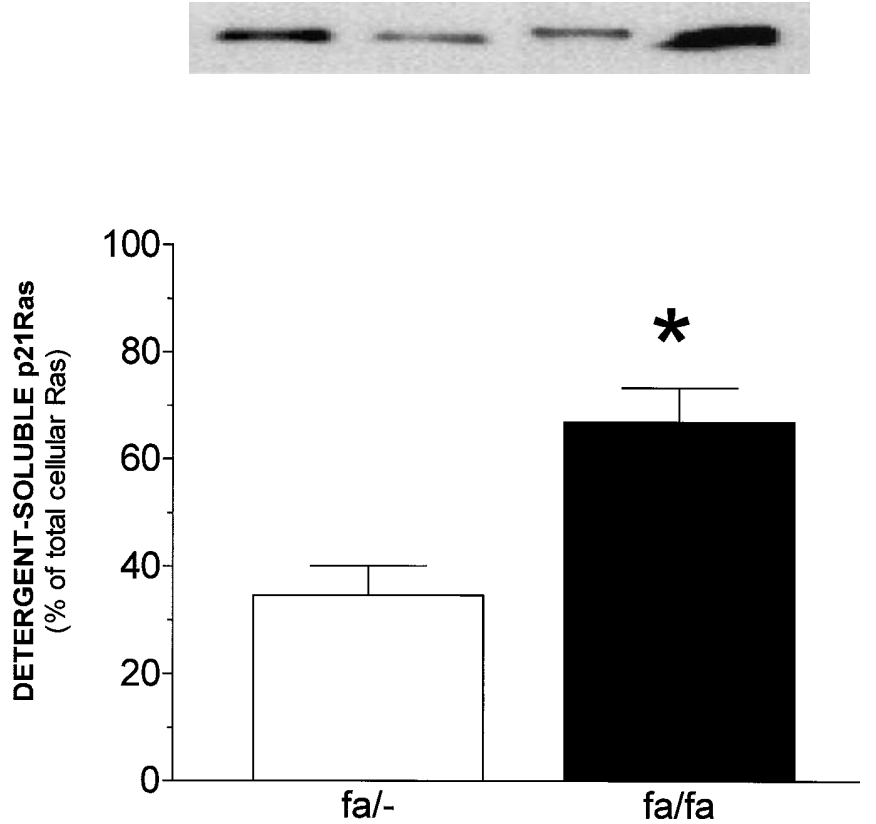

Fig. 2. Amounts of farnesylated (detergent-soluble) p21Ras in Zucker rat tissue. Crude lysate from liver was prepared as in Figure 1, and p21Ras was extracted from the aqueous (a) and detergent (d) phases and determined by Western blotting (upper panel) as described in Methods. Percentage of farnesylated p21Ras in lean [fa/-] (open bars) and obese [fa/fa] (solid bars) liver samples were compared (lower panel). Results represent the means \pm SEM, ${ }^{*}, p<0.01$ vs fa/- $(n=8)$

this association is not known, however, and the controversy that surrounds the identification of the culprit, hyperinsulinaemia vs insulin resistance, remains unresolved.

This debate can be resolved by showing or ruling out the direct detrimental influence of insulin on the arterial wall. Insulin has several potential targets in the arterial wall [i.e., endothelial cells, VSMC, and the indirect influence on either one of the two or both (for example, by way of lipids, advanced glycosylation end products, plasma factors, macrophages, etc.)]. In endothelial cells insulin promotes the synthesis of endothelin I [21] and the production of nitric oxide (NO) [22]. NO is the most potent vasodilator and inadequate production of NO results in considerable endothelial cell dysfunction [23]. Since the state of insulin resistance is associated with low NO production and endothelial cell dysfunction $[24,25]$ it was theorized that the lack of insulin's influence (secondary to the insulin resistance) is responsible for en-

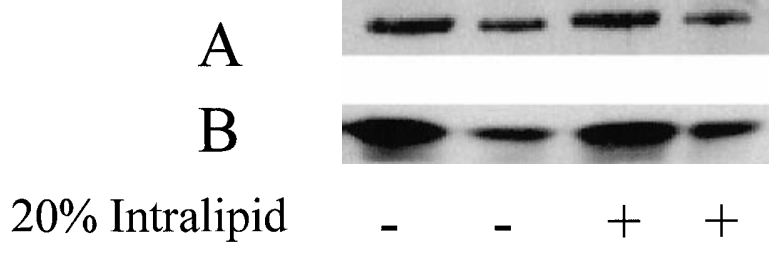

Fig.3 A, B. Effect of lipid on Triton X-114 extraction of farnesylated p21Ras from rat liver. Crude lysate from normal rat liver was prepared as described in Methods. Before Triton X114 extraction, the lysate was divided into equal volumes and $20 \%$ Intralipid $(50 \mu \mathrm{l})$ was added to one. (A) Endogenous p21Ras was immunoprecipitated from aqueous (a) and detergent (d) phases, and determined by Western blotting. (B) Bacterially expressed unprocessed p21Ras ( $\mathrm{rH}-\mathrm{Ras}, 250 \mathrm{nmol} / \mathrm{l})$ was added to the control and lipid-treated lysates. Aliquots were extracted with Triton X-114 and p21Ras was immunoprecipitated from the aqueous (a) and detergent (d) phases. Amounts of p21Ras were determined by Western blotting

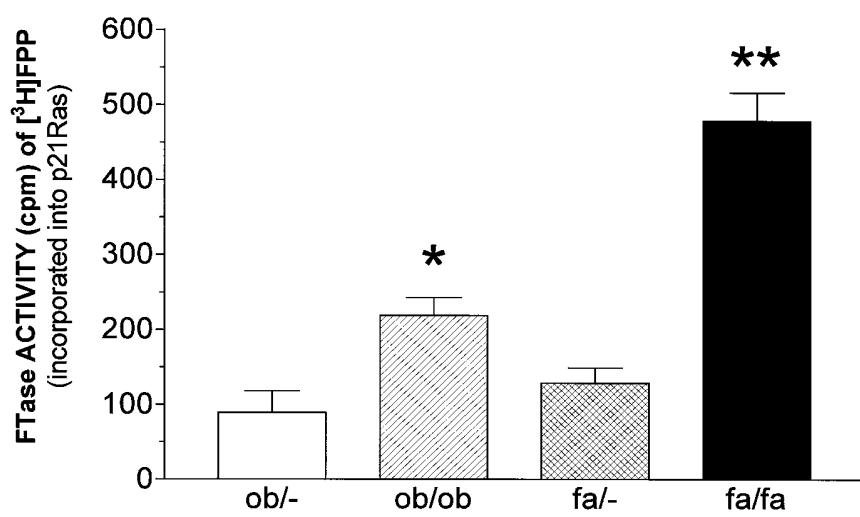

Fig. 4. FTase activity in liver extracts of obese and lean rodents. FTase activity was determined using the in vitro filtration assay, as described in Methods, in liver extracts of ob/(open bars), ob/ob (hatched bars), lean [fa/-] (cross-hatched bars), and fatty [fa/fa] (solid bars) Zucker rats. Results represent the means $\pm \mathrm{SEM}, *, p<0.05 \mathrm{vs} \mathrm{ob/-;} \mathrm{**,} p<0.01 \mathrm{vs} \mathrm{fa/-}$ $(n=3)$

dothelial cell dysfunction. Additionally, insulin has been shown to attenuate the influence of angiotensin II (A II) and vasopressin (AVP) [26, 27] and to affect the balance of the intracellular ions in VSMC [28, 29]. Therefore, in the state of insulin resistance, insulin can no longer attenuate the vasoconstrictive influence of A II and AVP, thus contributing to the progression of hypertension and atherosclerosis.

The most recent data from our laboratory [30] showed that in rat and porcine VSMC insulin increased the cellular pool of farnesylated p21Ras. This increase in farnesylated p21Ras was accompanied by potentiation of the effects of platelet-derived 

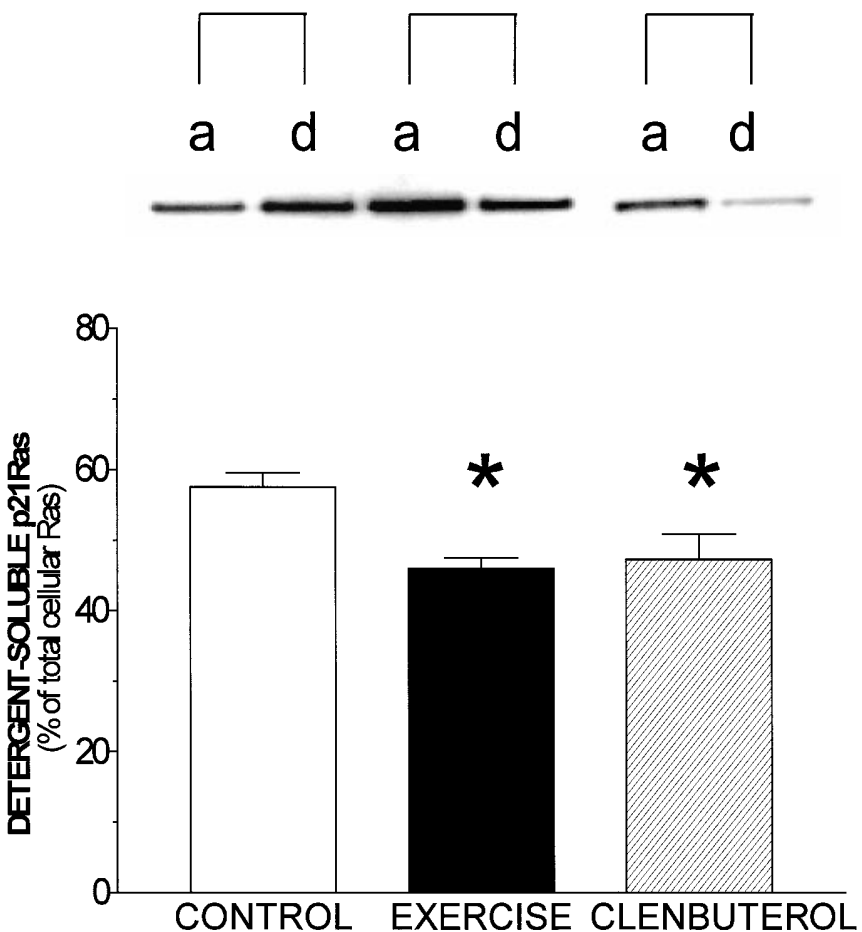

Fig.5. Effect of exercise training and clenbuterol treatment on the amounts of farnesylated p21Ras in Zucker liver tissue. Farnesylated p21Ras was determined, as described in Methods in liver samples of fatty [fa/fa] (control, open bar), exercised fatty (solid) and clenbuterol-treated fatty (hatched) Zucker rats. The upper panel is a representative experiment and the lower panel is a summary of 7-9 animals to a group. Results represent the means $\pm \mathrm{SEM}, *, p<0.05$ vs control (fa/fa) ( $n=7-9$ per group)

growth factor (PDGF) on thymidine incorporation (DNA synthesis) and the concentrations of messenger RNA of vascular endothelial growth factor (VEGF). VEGF increases the permeability of the endothelial cells which is considered to be an early step in the development of atherosclerosis [31-33]. Our observations are the first to implicate hyperinsulinaemia in the pathogenesis of the exaggerated nuclear responses of VSMC to growth factors. Conceivably, insulin resistance results in a decreased insulin effect on NO synthase in the endothelial cells whereas hyperinsulinaemia potentiates the PDGF-induced VEGF production in VSMC.

To further confirm hyperinsulinaemia increases the amounts of farnesylated p21Ras we measured the latter in control and denervated soleus rat muscle. Denervation produces insulin resistance within $24 \mathrm{~h}$ reducing the insulin-stimulated glucose transport and glycogen synthesis by $90 \%[14,15]$. Denervation of one hind limb did not change the concentrations of glycaemia or insulinaemia [14]. In contrast to the increased farnesylated p21Ras found in skeletal muscle of hyperinsulinaemic rodents, the levels of farnesylated p21Ras in denervated muscles of normoinsulinaemic rats remained the same. These observations indicate that hy-

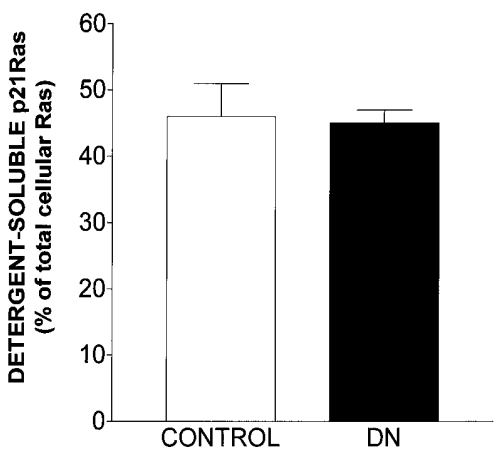

Fig. 6. Percentage of farnesylated p21Ras in control and denervated rat soleus muscle. p21Ras was immunoprecipitated from the aqueous and detergent-soluble fractions of control (open bar) and denervated (DN, closed bar) rat soleus muscle lysates. Relative amounts of p21Ras were determined by Western blotting. A summary of three independent experiments (means \pm SEM) is shown, representing the amount of farnesylated p21Ras (recovered from the detergent phase) as a percentage of total cellular p21Ras

perinsulinaemia and not insulin resistance promotes the increases in amounts of farnesylated p21Ras.

We also hypothesize that resistance to the metabolic aspects of insulin action (e.g., glucose transport) might not be accompanied by an equal reduction in the ability of insulin to activate FTase. We believe that hyperinsulinaemia, which is present in the state of insulin resistance, continues to stimulate FTase activity and thereby increases farnesylated p21Ras. When insulin resistance improved, we observed a reduction in the amounts of farnesylated p21Ras (Fig.4). Our preliminary experiments with a short-term hyperinsulinaemic clamp $(3 \mathrm{~h})$ in normal dogs and mice indicate that insulin infusion increases the amounts of farnesylated p21Ras in vivo (unpublished).

Insulin influences FTase [8-10]. We have shown that insulin promotes the phosphorylation and activation of FTase in various tissues [8-10]. Increased activity of FTase results in considerably increased farnesylated p21Ras. Farnesylated p21Ras is translocated to the plasma membrane where it can be activated by numerous growth factors and other agents that use the Ras signalling pathway. Among various growth factors only insulin is capable of activating FTase, whereas IGF-1, EGF, and PDGF have no effect on either FTase activity or the amounts of farnesylated p21Ras [34]. We hypothesized that the detrimental influence of insulin might be due to its ability to provide more farnesylated p21Ras molecules for activation by other agents. In support of this hypothesis we have shown that incubations of cells with insulin for 24 or $48 \mathrm{~h}$ significantly increased cellular responses to IGF-1, EGF or PDGF $[9,10]$. Thus, hyperinsulinaemia might create a new background for exaggerated cellular responses to signals mediated by the Ras pathway.

This study also supports this hypothesis by showing increased farnesylated p21Ras in tissues of hyper- 
insulinaemic animals. A reduction in the levels of insulinaemia corresponded to measurable decreases in farnesylated p21Ras. One might suggest that factors associated with obesity other than hyperinsulinaemia might increase FTase activity. One such factor could be tumour necrosis factor-alpha (TNF- $\alpha$ ), a cytokine found in excess in obesity and capable of inducing insulin resistance [35]. We have examined this possibility by measuring the amounts of farnesylated p21Ras in samples obtained from control and TNF- $\alpha$-treated rats (unpublished observations). The treatment with TNF- $\alpha$ did not change the amounts of farnesylated p21Ras and it does not appear likely that other abnormalities associated with obesity would have an influence. Further studies are needed to elucidate the causal relationship and pathophysiological significance of the association of hyperinsulinaemia and increased tissue levels of farnesylated p21Ras.

Acknowledgements. This study was supported by the Veteran's Administration Research Service, Foundation for Biomedical Education and Research, American Heart Association fellowship to (M. L. Goalstone), the Health One Foundation: Diabetes Research and Education Fund, Metabolex, Inc., American Diabetes Association (J. L. Ivy), and the National Institutes of Health (PO1 HL55854 and DK49147 to NR).We are grateful to J. Ventre, R. Meurer, and T. Doebber (Merck Research laboratories) for help in providing tissue samples and measurements of insulin and glucose concentrations in ob/ob, ob/-, and GTG-obese mice.

\section{References}

1. Bogulski MS, McCormick F (1993) Proteins regulating Ras and its relatives. Nature 366: 643-654

2. Burgering BMTH, Medema RH, Maassen JA, van de Wetering ML, van der El AJ, McCormick F, Bos JL (1991) Insulin stimulation of gene expression mediated by p21ras activation. EMBO J 10: $1103-1109$

3. Satoh T, Nakafuku M, Kaziro Y (1992) Interleukin 2-induced activation of Ras requires two domains of interleukin 2 receptor beta subunit, the essential region for growth stimulation and Lck-binding domain. J Biol Chem 267: 24149-24152

4. Draznin B, Chang L, Leitner JW, Takata Y, Olefsky JM (1993) Insulin activates p21Ras and guanine nucleotide releasing factor in cells expressing wild type and mutant insulin receptors. J Biol Chem 268: 19998-20001

5. Zhang FL, Casey PJ (1996) Protein prenylation: molecular mechanisms and functional consequences. Annu Rev Biochem 65: 241-269

6. Gutierrez L, Magee AI, Marshall CH, Hancock JF (1989) Posttranslational processing of p21ras is two-step and involves carboxyl-methylation and carboxy-terminal proteolysis. EMBO J 8: 1093-1098

7. Shaber MD, O’Hara UB, Garsky VD et al. (1990) Polyisoprenylation of Ras in vitro by a farnesyl-protein transferase. J Biol Chem 265: 14704

8. Goalstone ML, Draznin B (1996) Effect of insulin on farnesyltransferase activity in 3T3-L1 adipocytes. J Biol Chem 271: 27585-27589

9. Goalstone M, Carel K, Leitner JW, Draznin B (1997) Insulin stimulates the phosphorylation and activity of farnesyltransferase via the Ras-Mitogen-Activated protein kinase pathway. Endocrinology 138: 5119-5124

10. Leitner JW, Kline T, Carel K, Goalstone M, Draznin B (1997) Hyperinsulinemia potentiates activation of $\mathrm{p} 21 \mathrm{R}$ as by growth factors. Endocrinology 138: 2211-2214
11. Goalstone M, Leitner JW, Draznin B (1997) GTP loading of farnesylated p21ras by insulin at the plasma membrane. Biochem Biophys Res Commun 239: 42-45

12. Young JK, McKenzie JC, Brady LS, Herkenham M (1994) Hypothalamic lesions increase levels of neuropeptide Y mRNA in the arcuate nucleus in mice. Neurosci Lett 165: 13-17

13. Ventre J, Doebber T, Wu M et al. (1997) Targeted disruption of the tumor necrosis factor- $\alpha$ gene: metabolic consequences in obese and nonobese mice. Diabetes 46: 1526-1531

14. Heydrick SJ, Ruderman NB, Kurowski TG, Adams HB, Chen KS (1991) Enhanced stimulation of diacylglycerol and lipid synthesis by insulin in denervated muscle. Diabetes 40: 1707-1711

15. Saha AK, Kurowski TG, Ruderman NB (1995) A malonyl-CoA fuel-sensing mechanism in muscle: effects of insulin, glucose, and denervation. Am J Physiol 269(2 Pt 1):E283-E289

16. Torgan CE, Brozinick JT, Jr, Banks EA, Cortez MY, Wilcox RE, Ivy JL (1993) Exercise training and clenbuterol reduce insulin resistance in obese Zucker rats. Am J Physiol 264: E373-E379

17. Kuo C-H, Ding Z-P, and Ivy JL (1996) Interaction of exercise training and clenbuterol on GLUT-4 protein in muscle of obese Zucker rats. Am J Physiol 271: E847-E854

18. Reaven GM (1988) Banting Lecture 1988: Role of insulin resistance in human disease. Diabetes 37: 1595-1607

19. Laasko M, Lehto S (1997) Epidemiology of macrovascular disease in diabetes. Diabetes Rev 5: 294-315

20. Stout RW (1996) Hyperinsulinemia and atherosclerosis. Diabetes 45[Suppl 3]: 545-546

21. Oliver FJ, de la Rubia G, Ieener EP et al. (1991) Stimulation of endothelin-1 gene expression by insulin in endothelial cells. J Biol Chem 266: 23251-23256

22. Steinberg HO, Brechtel G, Johnson A, Fineberg N, Baron AD (1994) Insulin-mediated skeletal muscle vasodilatation is nitric oxid dependent. A novel action of insulin to increase nitric oxide release. J Clin Invest 94: 1172-1179

23. Rees DD, Palmer RM, Moncada S (1989) Role of endothelium-derived nitric oxide in the regulation of blood pressure. Proc Natl Acad Sci USA 86: 3375-3378

24. Baron AD (1996) Insulin and the vasculature - old actors, new roles. J Investig Med 44: 406-412

25. Scherrer U, Randin D, Vollenweider P, Vollenweider L, Nicod P (1994) Nitric oxide release accounts for insulin's vascular effect in humans. J Clin Invest 94: 2511-2515

26. Standley PR, Zhang F, Ram JL, Zemel MB, Sowers JR (1991) Insulin attenuates vasopression-induced calcium transients and a voltage-dependent calcium response in rat vascular smooth muscle cells. J Clin Invest 88: 1230-1236

27. Saito F, Hori MT, Fittingoff M, Hino T, Tuck ML (1993) Insulin attenuates agonist-mediated calcium mobilization in cultured rat vascular smooth muscle cells. J Clin Invest 92: 1161-1167

28. Standley PR, Ram JL, Sowers JR (1993) Insulin attenuation of vasopressin-induced calcium responses in arterial smooth muscle from Zucker rats. Endocrinology 133: 1693-1699

29. Dick GM, Sturek M (1996) Effects of a physiological insulin concentration on the endothelin-sensitive $\mathrm{Ca}^{2+}$ store in porcine coronary artery smooth muscle. Diabetes 45 : $876-880$

30. Goalstone ML, Natarajan R, Standley PR (1998) Insulin potentiates platelet-derived growth factor action in vascular smooth muscle cells. Endocrinology 139: 4067-4072

31. Leung DW, Cahianes G, Kuang W-J, Goeddel DV, Ferrara N (1989) Vascular endothelial growth factor is a secreted angiogenic mitogen. Science 246: 1306-1309

32. Williams B, Quinn-Baker A, Gallacher B (1995) Serum and platelet-derived growth factor-induced expression of vascular permeability factor mRNA by human vascular smooth muscle cells in vitro. Clin Sci 88: 141-147

33. Ferrara N, Houck K, Jakeman L, Leung DW (1992) Molecular and biological properties of the vascular endothelial growth factor family of proteins. Endocrinol Rev 13: 18-32

34. Goalstone ML, Leitner JW, Wall K, Dolgonos L, Rother KI, Accili D, Draznin, B (1998) Insulin's effect on farnesyltransferase: specificity of insulin action and potentiation of nuclear effects of IGF-1, EGF, and PDGF. J Biol Chem 273: 23892-23896

35. Hotamisligil GS, Murray DL, Choy LN, Spiegelman BM (1994) Tumor necrosis factor alpha inhibits signaling from the insulin receptor. Proc Natl Acad Sci USA 9: 4854-4858 